Société d'histoire de la révolution de 1848 et des

révolutions du XIXe siècle

$53 \mid 2016$

Mobilités, savoir-faire et innovations

\title{
Dominique KALIFA, Les bas-fonds. Histoire d'un imaginaire
}

Paris, Seuil, «L'Univers historique », 2013

Laurence Montel

\section{OpenEdition}

Journals

Édition électronique

URL : http://journals.openedition.org/rh19/5152

DOI : $10.4000 /$ rh19.5152

ISSN : $1777-5329$

Éditeur

La Société de 1848

Édition imprimée

Date de publication : 1 décembre 2016

Pagination : 209-212

ISSN : 1265-1354

Référence électronique

Laurence Montel, «Dominique KALIFA, Les bas-fonds. Histoire d'un imaginaire », Revue d'histoire du XIXe siècle [En ligne], 53 | 2016, mis en ligne le 21 février 2017, consulté le 23 septembre 2020. URL : http://journals.openedition.org/rh19/5152 ; DOI : https://doi.org/10.4000/rh19.5152

Ce document a été généré automatiquement le 23 septembre 2020

Tous droits réservés 


\title{
Dominique KALIFA, Les bas-fonds. Histoire d'un imaginaire
}

Paris, Seuil, « L’Univers historique », 2013

\author{
Laurence Montel
}

\section{RÉFÉRENCE}

Dominique KALIFA, Les bas-fonds. Histoire d'un imaginaire, Paris, Seuil, « L'Univers historique ", 2013, 395 p., $25 €$.

1 Dominique Kalifa propose dans ce livre un décryptage de l'imaginaire des bas-fonds, ces décors dans lesquels se déploient, depuis deux siècles, des récits de crime, et qui furent particulièrement ressassés des années 1820 aux années 1930. En mettant au jour ses significations, sa prégnance et sa diffusion dans un monde occidental transformé par l'industrialisation, il donne une nouvelle dimension à l'histoire des sociétés contemporaines vues depuis leurs marges. Le propos s'organise en trois grandes parties ordonnées chronologiquement mais portant sur les bas-fonds des regards de nature différente. La première détaille les éléments constitutifs de cet imaginaire, les conditions de son émergence et sa diffusion en occident des années 1820 aux années 1880, à partir d'un vaste corpus de textes européens et américains. Au-delà des variantes, les représentations des bas-fonds désignent toutes un même espace social caractéristique des villes modernes: des territoires insalubres abritant un "peuple» composite de marginaux et d'exclus vivant dans la misère, le vice, la violence et le crime. Faux et mauvais pauvres, voleurs et bohémiens en sont les figures masculines les plus saillantes, ainsi que les prisonniers, tandis que les prostituées représentent le genre féminin. Ce caravansérail ne forme pas un monde social en soi, cependant il le devient car par artifice on lui prête une langue secrète, des coutumes et des mœurs particulières, et une organisation collective (bandes, confréries, « monarchie d'argot »).

2 Cet imaginaire se diffuse dans les villes névralgiques de l'occident industrialisé dans le second XIX ${ }^{e}$ siècle. Dominique Kalifa rapproche cette circulation de celle des Mystères 
urbains, d'ailleurs très friands de bas-fonds, et la voit comme un élément de preuve supplémentaire de la globalisation en marche des cultures populaires. Les récits de basfonds participent en effet de la culture de masse dont ils respectent les contraintes génétiques, des jeux de contrastes, à la recherche de la sensation. Pourtant, souligne l'auteur, ils sont issus des peurs sociales des élites urbaines du premier XIX ${ }^{\mathrm{e}}$ siècle, confrontées aux dommages collatéraux de l'industrialisation que furent le paupérisme, l'exploitation des ouvriers ou les taudis, en un mot la question sociale. Supposant un lien étroit entre conditions de vie, dégradation des mœurs, crime et révolte, les bourgeoisies urbaines diabolisent les classes ouvrières et imaginent, dans les vieux quartiers inadaptés à la modernité et dans les faubourgs à la croissance anarchique, une société souterraine tapie, dangereuse, et prête à se révolter. C'est dans ces décennies, marquées aussi par l'essor des enquêtes sociales, que le mot "bas-fonds " prend cette signification socio-spatiale (underground en Angleterre) et que la matrice de cet imaginaire se forge, d'abord à Londres et à Paris. L'imaginaire des bas-fonds, poursuit l'auteur, puise dans un répertoire qui transcende les siècles et se renouvelle constamment, des motifs hérités de l'antiquité chrétienne (Sodome et Babylone), des temps médiévaux (mauvais pauvres, gueux) et modernes (cours des miracles, bandits), certains actualisés par le romantisme. Il se pare aussi de teintes exotiques et impériales (apaches parisiens, Thugs de Londres, « Dark continent»). Néanmoins c'est la peur des classes dangereuses et de l'émeute « vomie des bas-fonds » qui lui donne corps et force. La deuxième partie, "scénographies de l'envers social », rappelle que quel que soit le genre considéré (littératures, enquêtes sociales, images, chanson, cinéma), les basfonds sont d'abord des décors. Il est question ici de leur agencement et de la façon dont s'y déploient des intrigues à partir d'une lecture intensive du corpus francobritannique, assortie d'incursions régulières dans les sources et les bibliographies du continent américain. Des années 1840 aux années 1930, les bas-fonds font d'abord l'objet d'inventaires, de catalogues et de taxinomies. L' «empire des listes» (chapitre IV), qui participe de l'habitus policier dès le Moyen Âge, se propage au XIX ${ }^{\mathrm{e}}$ siècle dans les enquêtes sociales, la philanthropie, et les récits : il n'y a qu'un pas du contrôle des suspects à celui des pauvres, tandis que le panorama comme la typologie produisent l'illusion de faire vivre cette "société qui », de fait, «n'existe pas dans la réalité » (p.170).

Un processus d'immersion donne vie à ce décor. Il est particulièrement intéressant de constater que s'enfoncer dans les bas-fonds n'est pas réservé à des aventuriers d'encre et de papier, tels ces «princes déguisés » du premier XIXe siècle qui en constituent les visiteurs tutélaires, Haroun-al-Rachid, le calife des Mille et Une Nuits, et Rodolphe, le prince des Mystères de Paris. Des policiers, des détectives, des écrivains, des philanthropes et des réformateurs sociaux s'enfoncent dans les bas-fonds (on parle outre-manche de slumming) avant que les journalistes ne saturent le terrain. À ces périples, qui débouchent sur des récits voyeuristes mais pétris de morale, il faut ajouter le fashionable slumming, qui consiste à s'enfoncer dans les bas-fonds derrière un guide bien choisi, pour un moment de dépaysement, frisson garanti. Cette mode s'exporte à Paris et dans l'ensemble du monde occidental et colonial puis s'institutionnalise. On parle en France, dans les années 1890, de "tournée des grands ducs». Dans l'entredeux-guerres, elle devient un véritable "rite touristique » et fait la part belle à Montparnasse. La dernière modalité d'expérience des bas-fonds est celle des artistes convaincus que ces lieux seuls peuvent délivrer une vérité humaine dissimulée ailleurs. Incarnée d'après la bohème romantique, par le chiffonnier et plus largement les figures 
de la pauvreté, cette vérité est à chercher du côté de la pègre pour les artistes de Montmartre, au début du $\mathrm{XX}^{\mathrm{e}}$ siècle. Une ultime vague rejoue cette veine dans l'entredeux-guerres, entre fantastique social et réalisme poétique. Ce pouvoir d'attraction artistique des bas-fonds dresse un pont entre le Paris nocturne et mystérieux du milieu du XIX ${ }^{e}$ siècle, la chanson de rue des années 1900-1910, et le cinéma populiste des années 1930.

5 La dernière partie du livre, plus courte et plus composite, traite de l'affaissement incomplet de cet imaginaire au $\mathrm{XX}^{\mathrm{e}}$ siècle. Il est d'abord question de sa «lente résorption", en relation avec des transformations urbaines et sociales de fond: l'éradication des taudis, la fin de la criminalisation des pauvres et l'émergence de nouvelles représentations de la misère (immigrés, clochards, exclus des années 1970). Les mutations de l'économie criminelle jouent aussi, en portant sur le devant de la scène les trafiquants et les gangsters, qui se démarquent du «marécage social » des bas-fonds (p. 289). Tandis que se déploie l'imaginaire du Milieu, l'emploi à tout-va du mot «bas-fonds » témoigne de son épuisement. Ces derniers ne cessent pas pour autant de hanter les cultures occidentales: le chapitre IX se consacre à leurs résurgences au temps présent, en d'innombrables antimondes gothiques et fantastiques, dans le roman, la bande dessinée, le cinéma ou le jeu vidéo. Le livre se clôt sur un dernier chapitre plus anthropologique qu'historique, sur les «ressorts» de la "fascination » des sociétés contemporaines pour les bas-fonds, de la volonté de rendre compte des réalités sociales aux "désirs de bas-fonds", en passant par les intentions normalisatrices et dénonciatrices.

6 Ce livre est passionnant, non seulement parce qu'il se lit comme un roman et qu'il fait de vous un slummer averti, mais encore parce qu'il est un voyage multidimensionnel dans l'histoire et l'historiographie d'un long XIX siècle. Depuis l'ouvrage fondateur de Louis Chevalier, l'assimilation des classes laborieuses à des classes dangereuses par les bourgeoisies urbaines est une des lignes de force de cette histoire. Initialement portée par l'histoire sociale, cette question s'est déplacée sur le terrain de l'histoire culturelle - comme une preuve des peurs sociales du siècle. Souligner le lien étroit qui unit l'imaginaire des bas-fonds, l'industrialisation et les dynamiques de précarisation qu'elle entraîna, pour les classes ouvrières du premier XIX ${ }^{e}$ siècle, et les peurs sociales qui s'ensuivirent, revient à réinvestir cette question pour la systématiser et changer d'échelle puisque le regard passe des ouvriers à toute une société de l'envers, ce qui enrichit les perspectives de l'analyse. Le changement d'échelle passe aussi par l'attention portée à la circulation européenne et transatlantique de cet imaginaire, révélatrice de la dimension culturelle d'une globalisation abordée plus souvent dans ses dimensions démographiques et économiques.

7 Enfin, Dominique Kalifa prolonge ici la réflexion sur les enjeux de l'histoire culturelle. Le livre rappelle d'abord l'intérêt d'étudier en historien les productions littéraires, au moyen d'une méthode d'analyse textuelle et génétique propre à rendre intelligibles les imaginaires sociaux. En outre, en mettant particulièrement l'accent sur les transferts entre culture et société, il insiste sur les liens étroits et symbiotiques qui unissent les savoirs et les pratiques. On remarquera ici, en effet, que l'imaginaire des bas-fonds est performatif, qu'il engendre des pratiques qui sont autant d'expériences sensibles susceptibles à leur tour d'alimenter les imaginaires sociaux, ou de transformer le réel. On songe en particulier à l'exemple du slumming, cette descente dans les slums, que les Anglais désignent par l'expression « to go Haroun al Rashid » et qui réinvente la ville, 
entre fantasme et réel, dans un registre apolitique et nostalgique. Susceptible d'engendrer la patrimonialisation d'espaces-témoins de ces temps révolus, elle agit aussi sur l'imaginaire, qu'elle nourrit de son propre motif, mis en scène par la littérature ou le cinéma. L'étude fine de ces circulations entre le réel et l'imaginaire, est propre à convaincre - s'il le fallait en tout cas - de la portée de l'histoire culturelle, et de la fécondité d'une histoire des sociétés attentives aux discours qu'elles portent sur elles-mêmes (cf. la conclusion). 